\title{
Charge state of the activator in Ti:sapphire crystals grown by HDC method
}

\author{
N.S.Sidelnikova, S.V.Nizhankovskyi, V.V.Baranov \\ Institute for Single Crystals, STC "Institute for Single Crystals" National \\ Academy of Sciences of Ukraine, 60 Lenin Ave., 61001 Kharkiv, Ukraine
}

Received July 27, 2015

\begin{abstract}
The results of the study of the charge state of the activator $\left(\left[\mathrm{Ti}^{3+}\right],\left[\mathrm{Ti}^{4+}\right]\right)$ in Ti:sapphire crystals grown by the method of horizontal directed crystallization, are presented. It is shown that, depending on the pressure, the growth medium composition and the conditions of annealing of the crystals with $0.03-0.1$ wt. \% titanium content, the ratio of the content of the activator in the charge state $\left[\mathrm{Ti}^{4+}\right]$ to the one in $\left[\mathrm{Ti}^{3+}\right]$ state is $\approx 0.23-3.3 \%$. There are obtained approximate analytical dependences of $\left[\mathrm{Ti}^{4+}\right]$ and $\left[\mathrm{Ti}^{4+}\right] /\left[\mathrm{Ti}^{3+}\right]$ on the partial pressure of molecular oxygen and the total concentration of the activator which provide a reliable description of the experimental data. It is established that though with the growth of the total concentration of the activator the value of the ratio $\left[\mathrm{Ti}^{4+}\right] /\left[\mathrm{Ti}^{3+}\right]$ decreases to $\sim\left[\mathrm{Ti}_{\text {tot }}\right]^{-1 / 4}$, the concentration of the activator in the charge state $\mathrm{Ti}^{4+}$ rises to $\sim\left[\mathrm{Ti}_{\text {tot }}\right]^{3 / 4}$. This may be accompanied with the increase of the quantity of the absorption centers at $800 \mathrm{~nm}\left(\mathrm{Ti}^{3+}-\mathrm{Ti}^{4+}\right.$ centers) and, consequently with the figure of merit (FOM).
\end{abstract}

Keywords: Ti:sapphire, horizontal directed crystallization, absorption centers

Представлены результаты исследования зарядового состояния активатора $\left(\left[\mathrm{Ti}^{3+}\right],\left[\mathrm{Ti}^{4+}\right]\right)$ в кристаллах Ti:сапфира, выращенных методом горизонтальной направленной кристаллизации. Показано, что в зависимости от давления и состава атмосферы выращивания, условий отжига кристаллов с содержанием титана 0.03-0.1 wt. \%, соотношение количества активатора в зарядовом состоянии $\left[\mathrm{Ti}^{4+}\right] \kappa\left[\mathrm{Ti}^{3+}\right]$ составляет $\approx 0.23-3.3 \%$. Получены приближенные аналитические зависимости $\left[\mathrm{Ti}^{4+}\right]$ и $\left[\mathrm{Ti}^{4+}\right] /\left[\mathrm{Ti}^{3+}\right]$ от парциального давления молекулярного кислорода и общей концентрации активатора, обеспечивающие достоверное описание экспериментальных данных. Установлено, что хотя с ростом общей концентрации активатора величина соотношения $\left[\mathrm{Ti}^{4+}\right] /\left[\mathrm{Ti}^{3+}\right]$ снижается $\sim\left[\mathrm{Ti}_{\text {tot }}\right]^{-1 / 4}$, концентрация активатора в зарядовом состоянии $\left[\mathrm{Ti}^{4+}\right]$ растет $\sim\left[\mathrm{Ti}_{\text {tot }}\right]^{3 / 4}$, что может сопровождаться увеличением количества центров поглощения при $800 \mathrm{~nm}\left(\mathrm{Ti}^{3+}-\mathrm{Ti}^{4+}\right.$-центры) и, следовательно, снижением FOM.

Зарядовий стан активатора у кристалах Ті:сапфіру, вирощених методом ГСК. Н.С.Сідельнікова, С.В.Ніжанковський, В.В.Баранов.

Представлено результати дослідження зарядового стану активатора $\left(\left[\mathrm{Ti}^{3+}\right],\left[\mathrm{Ti}^{4+}\right]\right)$ у кристалах Ті:сапфіру, вирощених методом горизонтальної спрямованої кристалізації. Показано, що в залежності від тиску і складу атмосфери вирощування, умов відпалу кристалів з вмістом титану 0.03-0.1 wt.\%, співвідношення кількості активатора у зарядовому

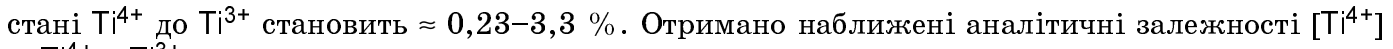
i $\left[\mathrm{Ti}^{4+}\right] /\left[\mathrm{Ti}^{3+}\right]$ від парціального тиску молекулярного кисню і загальної концентрації активатора, що забезпечують достовірний опис експериментальних даних. Встановлено, що хоча $з$ ростом загальної концентрації активатора величина співвідношення $\left[\mathrm{Ti}^{4+}\right] /\left[\mathrm{Ti}^{3+}\right]$ знижується $\sim\left[\mathrm{Ti}_{\text {tot }}\right]^{-1 / 4}$, концентрація активатора у зарядовому стані $\left[\mathrm{Ti}^{4+}\right]$ росте $\sim\left[\mathrm{Ti}_{\text {tot }}\right]^{3 / 4}$, що може супроводжуватися збільшенням кількості центрів поглинання при $800 \mathrm{~nm}$ ( $\mathrm{Ti}^{3+}-\mathrm{Ti}^{4+}$-центри) $\mathrm{i}$, отже, зниженням FOM. 


\section{Introduction}

Solid lasers based on titanium-doped sapphire (Ti:sapphire) are widely used in spectroscopy, measuring systems, facilities for treatment of metals, in various scientific investigations. At present the main techniques used for the obtaining of Ti:sapphire crystals for lasers are the Czhochralski, Kyropoulos, HEM (heat exchange method) methods and TGT (temperature gradient technology) [1-6]. As a rule, in these methods crystallization is realized in mixed argon and hydrogen atmosphere.

A promising technology for the obtaining of wide-aperture laser crystals is the method of horizontal directed crystallization (HDC) which uses carbon-containing constructional materials in the capacity of thermal insulation. This method is conventionally applied for the growth of large-size sapphire crystals with high optical quality and structure perfection [7]. In this case the reducing medium containing $\mathrm{CO}$ as a main component is formed spontaneously at the interaction of residual oxygen and water vapor with carbon (the lining material) [8-10]. Earlier in [10] we studied the use of this method for the obtaining of laser Ti:sapphire crystals $\left(100 \times 100 \times 35 \mathrm{~mm}^{3}\right)$ with the non-uniformity of titanium distribution $\Delta C_{\mathrm{Ti}} \leq 5 \%$ and the wave front distortion $\lambda / 5-\lambda / 10$ [10]. The results obtained while studying the distribution of color centers in Ti:sapphire crystals grown by the method of HDC in different reducing atmospheres were presented in [11].

One of the basic characteristics of Ti:sapphire crystals to be used in the capacity of active laser medium is their FOM:FOM = $K_{490} / K_{800}$, where $K_{490}$ is the absorption coefficient at $490 \mathrm{~nm}$ wavelength (the maximum of the optical absorption band of Ti:sapphire in the visible region of the spectrum), $K_{800}$, the absorption coefficient at $800 \mathrm{~nm}$ wavelength (the generation region for Ti:sapphire laser). Therefore, the possibility of commercial use of Ti:sapphire crystals as active laser elements to a considerable extent is defined by the value of optical loss at the generation wavelength $(\sim 800 \mathrm{~nm})$. As established in [12-15], the optical absorption band in this region of the spectrum is connected with the presence of the centers $\mathrm{Ti}^{3+}-\mathrm{Ti}^{4+}$ in the crystals. The intensity of this band depends on the relative content of the activator in the charge state $\mathrm{Ti}^{4+}$ which is defined by the value of the reduction potential of the growth me- dium, or by subsequent thermal treatment (the partial oxygen pressure in the technological medium).

The aim of the present work was to investigate the charge state of the activator in Ti:sapphire crystals grown by the method of HDC using carbon-containing constructional materials and subjected to additional annealing in different reducing atmospheres.

\section{Experimental}

Ti:sapphire crystals with $0.03-0.1$ wt. $\%$ titanium content and the dimensions 100$175 \times 100-175 \times 40 \mathrm{~mm}^{3}$ were grown at forevacuum pumping-out in the medium of $\mathrm{CO}$ $+\mathrm{H}_{2}$ under low pressure (0.01-0.3 Torr), and in argon atmosphere (800-950 Torr). In the former case the medium practically completely consists of the mixture of $\mathrm{CO}$ and $\mathrm{H}_{2}\left(P_{\mathrm{H}_{2}} / P_{\mathrm{CO}} \sim 0.02-0.04\right)$. In this case the total concentration of the reducing components $\left(\mathrm{CO}+\mathrm{H}_{2}\right)$ formed due to the interaction of the adsorbed oxygen and water vapour with the carbon graphite materials reached 1-5 vol.\% (amounted to several torr), depending on the preliminary vacuum technical procedure. In this connection, the relative contents of $\mathrm{CO}$ and $\mathrm{H}_{2}$ also changed within the limits $P_{\mathrm{H}_{2}} / P_{\mathrm{CO}} \approx 0.1-0.3$. The concentrations of $\mathrm{CO}$ and $\mathrm{H}_{2}$ in the gaseous medium were controlled using a gas chromatograph of "Crystal 2000M" type.

The crystallization rate was $1-2 \mathrm{~mm} / \mathrm{h}$. As a raw material, there were used broken $\mathrm{Al}_{2} \mathrm{O}_{3}$ crystals and $\mathrm{TiO}_{2}$ powder containing $\approx 10^{-4}$ wt. $\%$ of impurities. The optical investigations were realized on polished plane-parallel samples with the crystallographic orientation of the surface $(0001)$.

The transmission spectra $(T(\lambda, \%)$ of Ti:sapphire samples were registered on a Perkin-Elmer Lambda-35 spectrophotometer in 190-1100 $\mathrm{nm}$ range. The absorption spectra $\left(K\left(\lambda, \mathrm{cm}^{-1}\right)\right.$ were built after subtraction of the corrections for the reflection and the reduction to a unit of thickness [11].

The concentration of $\mathrm{T}^{3+}$ in the grown crystals was estimated from the empiric relation [16]:

$$
C\left(\mathrm{Ti}^{3+}\right)=K_{514} / 18.55 \mathrm{~cm}^{-1} \text {, wt. \% },
$$

where $K_{514}$ is the optical absorption coefficient at $514 \mathrm{~nm}$ wavelength.

After decomposition of the spectra $K(\lambda)$ into the Gaussian components [11], the con- 
centration of $\mathrm{Ti}^{4+}$ was estimated by means of the Smakula's equation:

$$
\begin{gathered}
{\left[\mathrm{Ti}^{4+}\right] \cdot f=} \\
=0.87 \cdot 10^{17} \cdot n \cdot\left(2+n^{2}\right)^{-2} \cdot K_{\max } \cdot \Delta, \mathrm{cm}^{-3},
\end{gathered}
$$

where $K_{\max }$ is the maximum value of the absorption coefficient $\lambda=225 \mathrm{~nm} ; \Delta$, the full peak width at half intensity; $n$, the refractive index at $\lambda=225 \mathrm{~nm}$ corresponding to $K_{\text {max }} ; f$, the oscillator strength (in the calculations we used $f=0.5$ taken from [17]).

We performed the thermodynamic analysis of the influence of the growth medium composition and the degree of the melt overheating on the concentration of titanium in the charge state $\mathrm{Ti}^{4+}$ in $\mathrm{Ti}$ :sapphire crystals using the data from [18]. In the mentioned paper devoted to the study of the defect structure of titanium-activated sapphire the authors established the temperature dependence of the equilibrium constant for the redox reaction defining the valence state of titanium as a function of the partial oxygen pressure:

$$
\begin{gathered}
\frac{3}{4} \mathrm{O}_{2}(g)+3 \mathrm{Ti}_{\mathrm{A} l} \rightleftarrows 3 \mathrm{Ti}_{\mathrm{Al}}+V^{\prime \prime \prime}{ }_{\mathrm{A} l}+\frac{3}{2} \mathrm{O}_{\mathrm{O}}^{\times}, \\
K_{o x, V}^{\mathrm{Ti}}= \\
=4.99 \cdot 10^{2} \cdot \exp (7.08 \mathrm{eV} / k T) a t m^{-3 / 4} \mathrm{~cm}^{-3} .
\end{gathered}
$$

In accordance with the mass action law, the equilibrium constant (4) has the form:

$$
\left.K_{o x, V}^{\mathrm{Ti}}=\frac{\left[\mathrm{Ti}_{\mathrm{A}}\right]^{3}}{\left[\mathrm{Ti}_{\mathrm{A}}\right]^{3}}\right]^{3} \cdot\left[V_{\mathrm{A},}^{\prime \prime \prime}\right] \cdot P_{\mathrm{O}_{2}}^{-3 / 4} \text {, }
$$

where $\left[\mathrm{Ti}_{\mathrm{Al}}^{\circ}\right]$ is the concentration of the activator in the charge state $\mathrm{Ti}^{4+} ;\left[\mathrm{Ti}_{\mathrm{A},}\right]^{3}$, the concentration of the activator in the charge state $\mathrm{Ti}^{3+} ;,\left[V_{\mathrm{Al}}^{\prime \prime}\right]$ the concentration of $\mathrm{Al}$ vacancies $\left(\mathrm{cm}^{-3}\right) ; P_{\mathrm{O}_{2}}$, the pressure of molecular oxygen in $\mathrm{Al}_{2} \mathrm{O}_{3}$ vapour phase (atm).

Under the neutral conditions

$$
\begin{gathered}
{\left[\mathrm{Ti}_{\mathrm{Al}}^{\circ} \approx 3 \cdot\left[V^{\prime \prime \prime} \mathrm{Al}\right],\right.} \\
K_{O x, V}^{\mathrm{Ti}}=\frac{\left[\mathrm{Ti}_{\mathrm{A}}^{\circ}\right]^{4}}{3 \cdot\left[\mathrm{T}_{\mathrm{A} I}^{\mathrm{x}}\right]^{3}} \cdot P_{\mathrm{O}_{2}}^{-3 / 4} .
\end{gathered}
$$

Using (4) and (7) from [18] one can obtain the expression for the numerical estimation of $\left[\mathrm{Ti}^{4+}\right] /\left[\mathrm{Ti}^{3+}\right]$ value under different conditions $\left(T, P_{\mathrm{O}_{2}}\right)$ :

$$
\frac{\left[\mathrm{Ti}_{\mathrm{tot}}\right]}{3 \cdot K_{o x, V}^{\mathrm{Ti}} \cdot P_{O_{2}^{3}}^{3 / 4}} \cdot X^{4}-X-1=0
$$

where $X=\left[\mathrm{Ti}^{4+}\right] /\left[\mathrm{Ti}^{3+}\right] ;\left[\mathrm{Ti}_{\text {tot }}\right]=\left[\mathrm{Ti}^{3+}\right]+\left[\mathrm{Ti}^{4+}\right]$ is the total activator concentration, and estimate the corresponding value of $\left[\mathrm{Ti}^{4+}\right]$ :

$$
\left[\mathrm{Ti}^{4+}\right]=\left(1+\left[\mathrm{Ti}^{4+}\right] /\left[\mathrm{Ti}^{3+}\right]\right)^{-1} \cdot\left[\mathrm{Ti}_{\text {tot }}\right] \text {. }
$$

When the concentration of titanium in Ti:sapphire is less than 1 wt. \%, it can be assumed that the pressure of oxygen in the gaseous phase over Ti:sapphire to a sufficient degree of accuracy coincides with the pressure of oxygen in the vapour phase over $\mathrm{Al}_{2} \mathrm{O}_{3}$. The calculations of the pressure of molecular oxygen in the vapour phase of $\mathrm{Al}_{2} \mathrm{O}_{3}$ in the reducing gaseous mixtures $\mathrm{CO}+\mathrm{H}_{2}$ and $\mathrm{Ar}+\mathrm{CO}+\mathrm{H}_{2}$ of different composition were made according to the earlier proposed methods described in detail in $[9,19]$ using the reference thermodynamic data from [20-22]. The calculations were realized for vacuum and $\mathrm{CO}+\mathrm{H}_{2}$ mixtures under the pressures ranging between 0.0001 and 2 Torr. The calculations for $\mathrm{Ar}+\mathrm{CO}+\mathrm{H}_{2}$ mixtures were made under the conditions of the total pressure 800 Torr and the partial pressure of the reducing component $\mathrm{CO}+\mathrm{H}_{2}\left(P_{\text {red }}\right)$ varying from 0.0001 to 12 Torr at the ratio $P_{\mathrm{H}_{2}} / P_{\mathrm{CO}}$ in the mixture ranging from 0.01 to 1. Such compositions of the mixtures completely overlap the interval of real conditions for the growth of sapphire and Ti:sapphire by the method of HDC using carbon-containing constructional materials [9-11].

The calculations for $\left[\mathrm{Ti}^{4+}\right] /\left[\mathrm{Ti}^{3+}\right]$ and $\left[\mathrm{Ti}^{4+}\right]$ were carried out under the neutral conditions of vacuum and $\mathrm{Ar}$ atmosphere and reducing conditions in $\mathrm{CO}+\mathrm{H}_{2}$ and $\mathrm{Ar}+\mathrm{CO}+\mathrm{H}_{2}$ mixtures for activator concentration $\left(\left[\mathrm{Ti}_{\text {tot }}\right]\right)$ from 0.01 to 0.4 wt $\%$ $\left(\approx 3 \cdot 10^{18}-10^{20} \mathrm{~cm}^{-3}\right)$.

Peculiarities of the obtained dependences $\left[\mathrm{Ti}^{4+}\right] /\left[\mathrm{Ti}^{3+}\right]$ (Fig. 1) on the partial pressure of the reducing component $P_{\text {red }}=P_{\mathrm{CO}}+P_{\mathrm{H}_{2}}$ are defined by the character of the change in the composition of vapour $\mathrm{Al}_{2} \mathrm{O}_{3}$ phase under stationary conditions of evaporation in media with different composition.

\section{Results and discussion}

As earlier shown in $[9,19]$, in the inert medium the dependence of $P_{\mathrm{O}_{2}}$ on $P_{m}$ is 

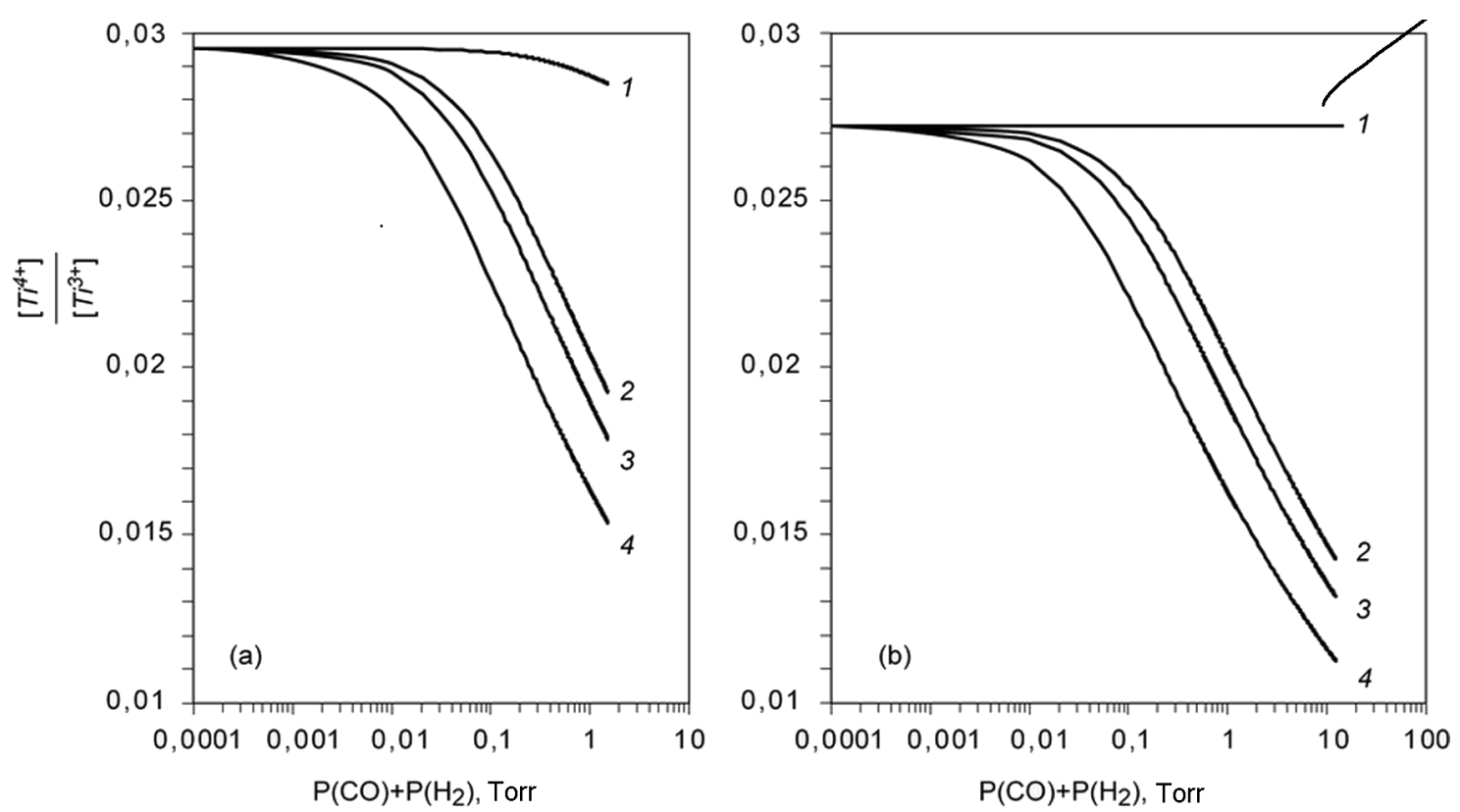

Fig. 1. Calculated values of the ratio $\left[\mathrm{Ti}^{4+}\right] /\left[\mathrm{Ti}^{3+}\right]$ at $T=2327 \mathrm{~K}, C\left(\mathrm{Ti}_{\text {tot }}=0.05\right.$ wt $\%$ : (a) in a media under low pressure on the total pressure in vacuum (curve 1) and in $\mathrm{CO}+\mathrm{H}_{2}$ medium at the ratios $P_{\mathrm{H}_{2}} / P_{\mathrm{CO}}=0.01, P_{\mathrm{H}_{2}} / P_{\mathrm{CO}}=0.1, P_{\mathrm{H}_{2}} / P_{\mathrm{CO}}=1$, curves $2,3,4$, respectively; (b) in the neutral Ar medium at a pressure of 800 Torr (curve 1) and in $\mathrm{Ar}+\mathrm{CO}+\mathrm{H}_{2}$ medium, on the partial pressure of the reducing component $\left(P_{\mathrm{CO}}+P_{\mathrm{H}_{2}}\right)$ at the ratios $P_{\mathrm{H}_{2}} / P_{\mathrm{CO}}=0.01, P_{\mathrm{H}_{2}} / P_{\mathrm{CO}}=0.1, P_{\mathrm{H}_{2}} / P_{\mathrm{CO}}=1$, curves $2,3,4$, respectively.

weak and defined predominantly by the transition from molecular to diffusion evaporation under pressures lower than 10 Torr. The dependence of $P_{\mathrm{O}_{2}}$ on $P_{\text {red }}$ is more essential. For $P_{\text {red }} \leq 0.01$ Torr the composition of the vapour over $\mathrm{Al}_{2} \mathrm{O}_{3}$ melt is predominantly defined by the value of the total pressure of the medium, for $P_{\text {red }} \approx 0.01-0.1$ Torr there exists an intermediate region where the influence of the reduction reactions starts to manifest itself. With the rise of the total pressure of the reducing components and of the ratio $P_{\mathrm{H}_{2}} / P_{\mathrm{CO}}$ the reducing properties of the gaseous medium also increase. Under $P_{\text {red }}>0.1$ Torr the reducing reactions become determinative. In these reactions (the interaction between $\mathrm{Al}_{2} \mathrm{O}_{3}$ and the products of its dissociation with the reducing components $\mathrm{CO}$ and $\mathrm{H}_{2}$ ) the loss of oxygen takes place not only in the composition of the oxygen-containing products of $\mathrm{Al}_{2} \mathrm{O}_{3}$ thermal dissociation, but also in the composition of $\mathrm{CO}_{2}$ and $\mathrm{H}_{2} \mathrm{O}$ (the products of the reducing reactions). Accordingly, in the inert medium with $P_{m}$ changing from 0.0001 Torr to atmospheric pressure the value of decreases less than by $10 \%$ (curves 1, Fig. 1). In the media which contain the reducing components at $P_{\text {red }}<$ 0.01 Torr the decrease of $\left[\mathrm{Ti}^{4+}\right] /\left[\mathrm{Ti}^{3+}\right]$ is more noticeable. At $P_{\text {red }}>0.01$ Torr this effect increases, and the rise of the contribution of hydrogen which is more intense reducer leads to more intense decrease.

Even in the case of the neutral conditions (i.e. vacuum or argon atmosphere) the calculated $\left[\mathrm{Ti}^{4+}\right] /\left[\mathrm{Ti}^{3+}\right]$ values do not exceed 0.05 (Fig. 1). Therefore, when assuming $\left[\mathrm{Ti}^{3+}\right] \approx\left[\mathrm{Ti}_{\text {tot }}\right]$ in (7), and $X<1$ in (8), these expressions can be used for obtaining approximate dependences of $\left[\mathrm{Ti}^{4+}\right]$ and $\left[\mathrm{Ti}^{4+}\right] /\left[\mathrm{Ti}^{3+}\right]$ on the partial pressure of molecular oxygen and the total activator concentration:

$\left[\mathrm{Ti}^{4+}\right] \approx\left(3 \cdot K_{o x, V}^{\mathrm{Ti}}\right)^{1 / 4} \cdot\left(P_{\mathrm{O}_{2}}\right)^{3 / 16} \cdot\left[\mathrm{Ti}_{t o t}\right]^{3 / 4}, \mathrm{~cm}^{-1}$,

$\frac{\left[\mathrm{Ti}^{4+}\right]}{\left[\mathrm{Ti}^{3+}\right]} \approx\left(3 \cdot K_{o x, V}^{\mathrm{Ti}}\right)^{1 / 4} \cdot\left(P_{\mathrm{O}_{2}}\right)^{3 / 16} \cdot\left[\mathrm{Ti}_{t o t}\right]^{-1 / 4}$.

The $P_{\mathrm{O}_{2}}$ comparison of the expressions (8), (11) and (9), (10) shows that the approximate estimations of $\left[\mathrm{Ti}^{4+}\right] /\left[\mathrm{Ti}^{3+}\right]$ are lower than the exact solution of (8), whereas the estimations of $\left[\mathrm{Ti}^{4+}\right]$ are higher than the ones obtained according to (9). The exact and approximate values of $\left[\mathrm{Ti}^{4+}\right] /\left[\mathrm{Ti}^{3+}\right]$ 

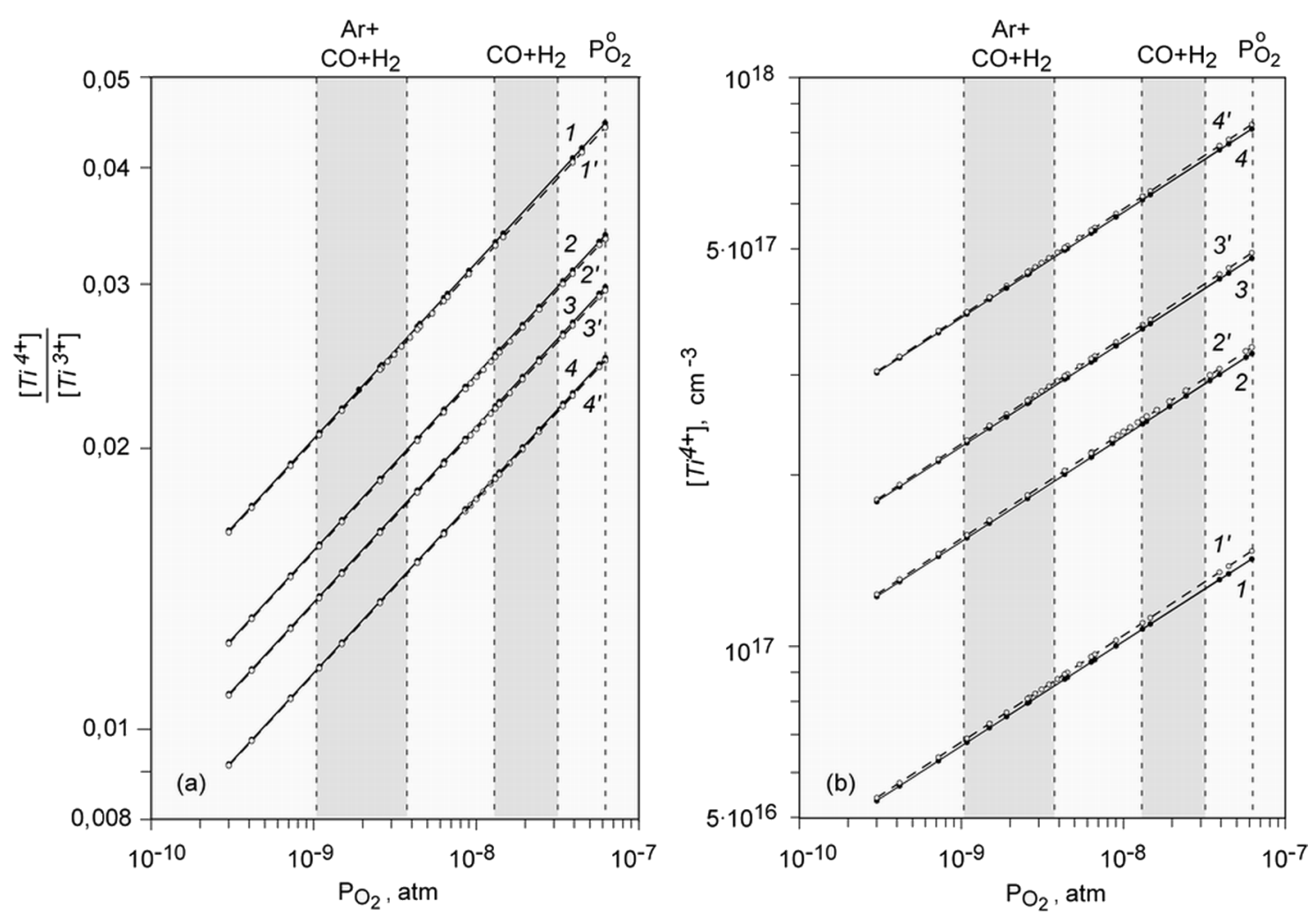

Fig. 2. Values of $\left[\mathrm{Ti}^{4+}\right] /\left[\mathrm{Ti}^{3+}\right]$ (a) and $\left[\mathrm{Ti}^{4+}\right]$ (b) under changing $P_{\mathrm{CO} 2}$ in $\mathrm{Al}_{2} \mathrm{O}_{3}$ vapour phase in media with different composition at $T=2327 \mathrm{~K}$. The dependences $1,2,3,4$ are the exact calculations according to $(6),(7) ; 1^{\prime}, 2^{\prime}, 3^{\prime}, 4^{\prime}$ are the approximate estimations according to (9), (8) at $C\left(\mathrm{Ti}_{\text {tot }}\right)=$ $0.01,0.03,0.05,0.1$ wt. $\%$, respectively.

and depending on the partial pressure of oxygen are presented in Fig. 2. Marked here are the intervals $P_{\mathrm{O}_{2}}$ corresponding to the conditions of the growth in the inert medium (vacuum or $\mathrm{Ar}$ atmosphere), and in the reducing media $\mathrm{CO}+\mathrm{H}_{2}$ and $\mathrm{Ar}+\mathrm{CO}+\mathrm{H}_{2}$. It is seen that the distinctions between the exact and approximate values are not essential, they do not exceed $\sim 1 \%$ and diminish when $\left[\mathrm{Ti}^{4+}\right] /\left[\mathrm{Ti}^{3+}\right]$ values decrease with the rise of the reduction potential of the medium (i.e. with the diminution of the partial pressure of oxygen in the vapour phase of $\mathrm{Al}_{2} \mathrm{O}_{3}$ ). The graphs are presented in double logarithmic scale to clearly illustrate the presence of the power dependences of $\left[\mathrm{Ti}^{4+}\right] /\left[\mathrm{Ti}^{3+}\right]$ and $\left[\mathrm{Ti}^{4+}\right]$ on for the exact solution.

It is interesting to study the peculiarities of the temperature dependence of $\left[\mathrm{Ti}^{4+}\right] /\left[\mathrm{Ti}^{3+}\right]$ (Fig. 3a), bound up with different temperature dependences of $K_{o x, V}^{\mathrm{Ti}}$ (4) and $P_{\mathrm{O}_{2}}$ (Fig. 3, b) and the above-considered character of the change in the composition of vapour $\mathrm{Al}_{2} \mathrm{O}_{3}$ phase in media of different compositions.
As the temperature rises, the value of $\left[\mathrm{Ti}^{4+}\right] /\left[\mathrm{Ti}^{3+}\right]$ in vacuum and the inert medium decreases (dependences 1, 2, Fig. 3a), in the media with relatively high reduction potential it grows (dependence 6, Fig. 3). In the media with relatively low reduction potential, that corresponds to the growth of crystals in low-pressure media, (the dependences 3-5, Fig. 3a), the considered value has a maximum (at low temperatures it rises, at high temperatures decreases). The position of the maximum depends on the composition of the reducing medium. This is connected with the peculiarities of the temperature dependence of $\mathrm{P}_{\mathrm{O}_{2}}$ in $\mathrm{Al}_{2} \mathrm{O}_{3}$ vapor phase in different media. In (10) and (11) the temperature-dependent parameters are $K_{o x, V}^{\mathrm{Ti}}$ and $P_{\mathrm{O}_{2}}$, thereat, the value of $K_{o x, V}^{\mathrm{Ti}} \sim \exp (7.08 / k T)$ diminishes as the temperature rises, whereas the value of $P_{\mathrm{O}_{2}}$ rises. The estimations show that at temperatures lower than $2000 \mathrm{~K}$ in the inert phase $P_{\mathrm{O}_{2}} \sim \exp (-7.33 / k T)$ (the dependences 1, 2, Fig. $3 b)$, in the medium containing the reducing components $P_{\mathrm{O}_{2}} \sim \exp (-11.8 / k T)$ (the 

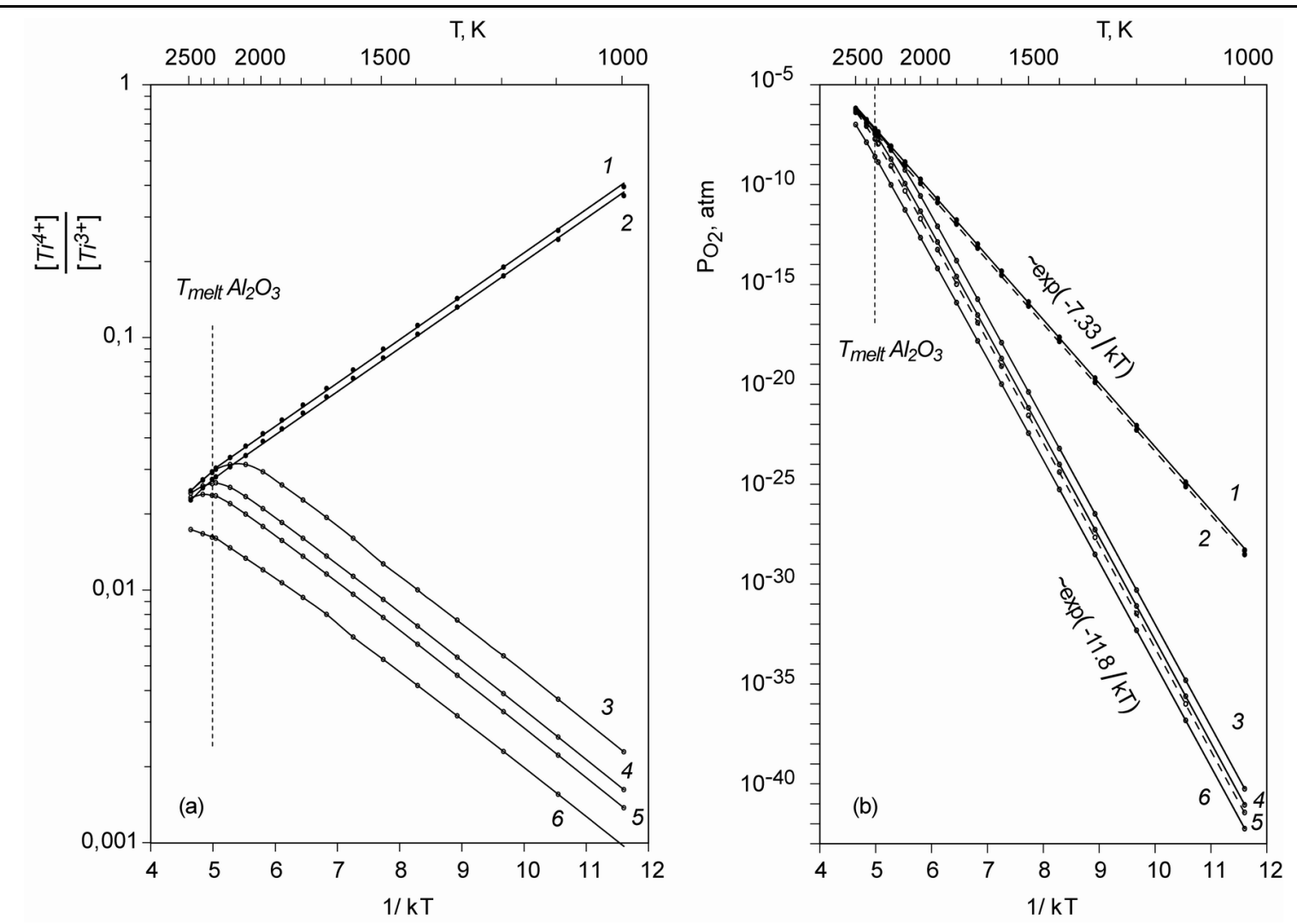

Fig. 3. Temperature dependences $\left[\mathrm{Ti}^{4+}\right] /\left[\mathrm{Ti}^{3+}\right]$ (a) and $P_{\mathrm{O} 2}$ in $\mathrm{Al}_{2} \mathrm{O}_{3}$ vapour phase (b): (1) in vacuum (0.0001 Torr); (2) in the inert Ar medium (800 Torr); (3), (4), (5) in $\mathrm{CO}+\mathrm{H}_{2}$ medium under pressures of 0.01, 0.1, 0.3 Torr, $P_{\mathrm{H}_{2}} / P_{\mathrm{CO}}=0.01 ;(6)$ in $\mathrm{Ar}+\mathrm{CO}+\mathrm{H}_{2}$ medium (800 Torr), $P_{r e}=3$ Torr, $P_{\mathrm{H}_{2}} / P_{\mathrm{CO}}=0.1$.

dependences 3-6, Fig. 3b). In other words, the absolute value of the exponent rises as the reducing properties of the medium increase. Accordingly, at low temperatures the product $\left(3 \cdot K_{o, V}{ }^{\mathrm{Ti}}\right)^{1 / 4} \cdot P_{\mathrm{O}_{2}}{ }^{3 / 16}$ which defines the temperature dependence of $\left[\mathrm{Ti}^{4+}\right] /\left[\mathrm{Ti}^{3+}\right]$ and $\left[\mathrm{Ti}^{4+}\right]$ in the neutral medium is $\sim \exp (0.4 / k T)$, in the medium containing the reducing components it is $\sim \exp (0.4 / k T)$. The largest distinction between the dependences $P_{\mathrm{O}_{2}}(T)$ in $\mathrm{Al}_{2} \mathrm{O}_{3}$ vapour phase in the inert medium and in the medium which contains the reducing components is observed at low temperatures when the contribution of thermal dissociation is minimal. With the growth of the temperature this contribution increases, the absolute value of the exponent $P_{\mathrm{O}_{2}}(T)$ diminishes and approaches the value characteristic of the one for the inert medium. Thereat, with the growth of the reducing properties of the medium the exponential dependence $P_{\mathrm{O}_{2}}(T) \sim \exp (-11.8 / k T)$ holds true at higher temperatures, that is seen when com- paring the dependences 3 and 6 , Fig. $3 \mathrm{~b}$. Therefore, in the media with relatively low reduction potential at reaching certain conditions the exponent which defines the temperature dependence of the product $\left(3 \cdot K_{o x, V}^{\mathrm{Ti}}\right)^{1 / 4} \cdot P_{\mathrm{O}_{2}}{ }^{3 / 16}$, reverses its sign. This testifies to the presence of a maximum of the temperature dependences of $\left[\mathrm{Ti}^{4+}\right] /\left[\mathrm{Ti}^{3+}\right]$ and $\left[\mathrm{Ti}^{4+}\right]$ under such conditions (the dependences 3-5, Fig. 3a).

The data presented in Fig. 3a show that at the growth of the crystals in vacuum, in the inert medium and the medium $\mathrm{CO}+\mathrm{H}_{2}$ under low (0.01-0.1 Torr) pressure, the rise of the degree of the melt overheating is accompanied with the decrease of the values of $\left[\mathrm{Ti}^{4+}\right] /\left[\mathrm{Ti}^{3+}\right]$ and $\left[\mathrm{Ti}^{4+}\right]$. At further rise of the pressure such an effect is practically absent. At the growth of the crystals in $\mathrm{Ar}$ atmosphere with 1-5 vol.\% concentration of the reducing component $\mathrm{CO}+\mathrm{H}_{2}$ an essential increase of the degree of the melt overheating is not expedient since this raises $\left[\mathrm{Ti}^{4+}\right] /\left[\mathrm{Ti}^{3+}\right]$ and $\left[\mathrm{Ti}^{4+}\right]$.

While analyzing the approximate dependences (10), (11) one can see that with the 

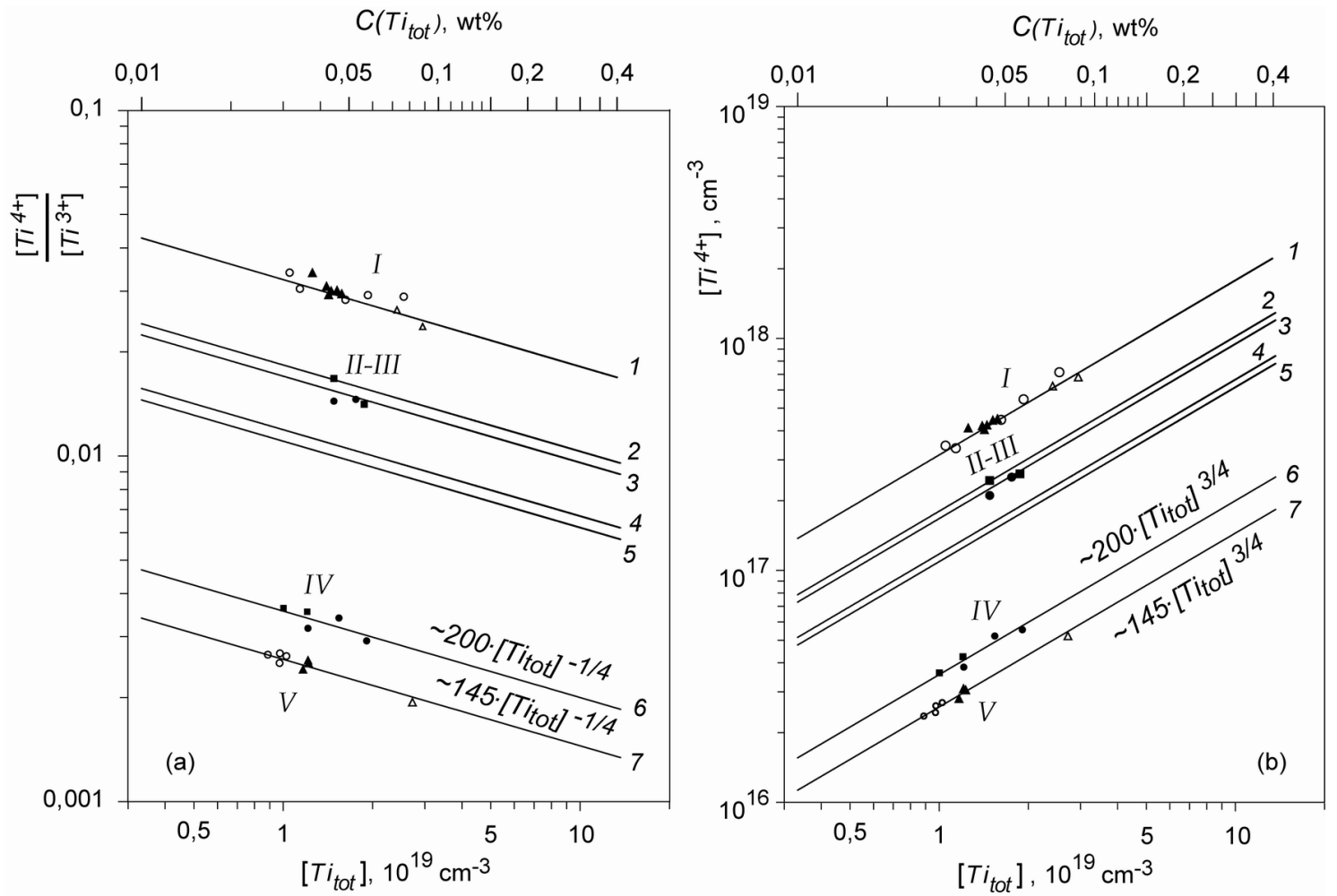

Fig. 4. Calculated and experimental values of $\left[\mathrm{Ti}^{4+}\right] /\left[\mathrm{Ti}^{3+}\right]$ (a) and $\left[\mathrm{Ti}^{4+}\right]$ (b) at changing $\left[\mathrm{Ti}_{\text {tot }}\right]$ for media of different composition: $1,2,3,4,5$ are calculated at the values of $T, P_{m}, P_{r e}, P_{\mathrm{H}_{2}} / P_{\mathrm{CO}}$ given in Table 1; 6, 7 - according to (11) (a) and (10) (b). Points denote the experimental data for the crystals grown at $\mathrm{P}(\mathrm{CO}+\mathrm{H} 2) \approx 0.03-0.05$ Torr $(\mathrm{I})$, in $\mathrm{Ar}+\mathrm{CO}+\mathrm{H} 2$ medium, $\mathrm{Pm}=800$ Torr, Pred $=3-5$ Torr (II-III) and after additional reducing annealing at $T=1900 \mathrm{~K} \mathrm{Ar}+\mathrm{CO}+\mathrm{H}_{2}$ medium, $P_{m}=800 \mathrm{Torr}$, $P_{\text {red }} \approx 3-5$ Torr (IV, V).

growth of $\left[\mathrm{Ti}_{\text {tot }}\right]$ the ratio $\left[\mathrm{Ti}^{4+}\right] /\left[\mathrm{Ti}^{3+}\right]$ diminishes whereas $\left[\mathrm{Ti}^{4+}\right]$ rises, and the latter may be accompanied with the increase of the quantity of the centers $\left(\mathrm{Ti}^{3+}-\mathrm{Ti}^{4}\right)$ which define the optical absorption at $800 \mathrm{~nm}$ and, consequently, with the decrease of the FOM. It should be noted that the data concerning the tendency to the FOM decrease at the rise of the activator concentration have also been reported by other authors [2, 23], and are contained in the commercial infor- mation presented e.g. by the website of GT Advanced Technologies [24].

In spite of essential assumption, the results of the performed calculations to a sufficient accuracy coincide with the experimental data (Fig. 4). So, the above-described thermodynamic approach can be used while estimating the degree of the activator reduction in the Ti-sapphire crystals grown in the media containing the reducing components. Fig. 4 presents the calculated (solid lines) and experimental (separate

Table. Parameters used in theoretical estimations of $\left[\mathrm{Ti}^{4+}\right] /\left[\mathrm{Ti}^{3+}\right]$ and $\left[\mathrm{Ti}^{4+}\right]$ values

\begin{tabular}{|c|c|c|c|c|c|}
\hline Number & $\begin{array}{c}\text { Composition of } \\
\text { the medium }\end{array}$ & $T, \mathrm{~K}$ & $P_{m}$, Torr & $P_{\text {red }}$, Torr & $P_{\mathrm{H}_{2}} / P_{\mathrm{CO}}$ \\
\hline 1 & $\mathrm{CO}+\mathrm{H}_{2}$ & 2327 & 0.03 & 0.03 & 0.01 \\
2 & $\mathrm{Ar}+\mathrm{CO}+\mathrm{H}_{2}$ & 2327 & 800 & 3 & 0.1 \\
3 & $\mathrm{Ar}+\mathrm{CO}+\mathrm{H}_{2}$ & 2327 & 800 & 5 & 0.1 \\
4 & $\mathrm{Ar}+\mathrm{CO}+\mathrm{H}_{2}$ & 1900 & 800 & 3 & 0.1 \\
5 & $\mathrm{Ar}+\mathrm{CO}+\mathrm{H}_{2}$ & 1900 & 800 & 5 & 0.1 \\
\hline
\end{tabular}




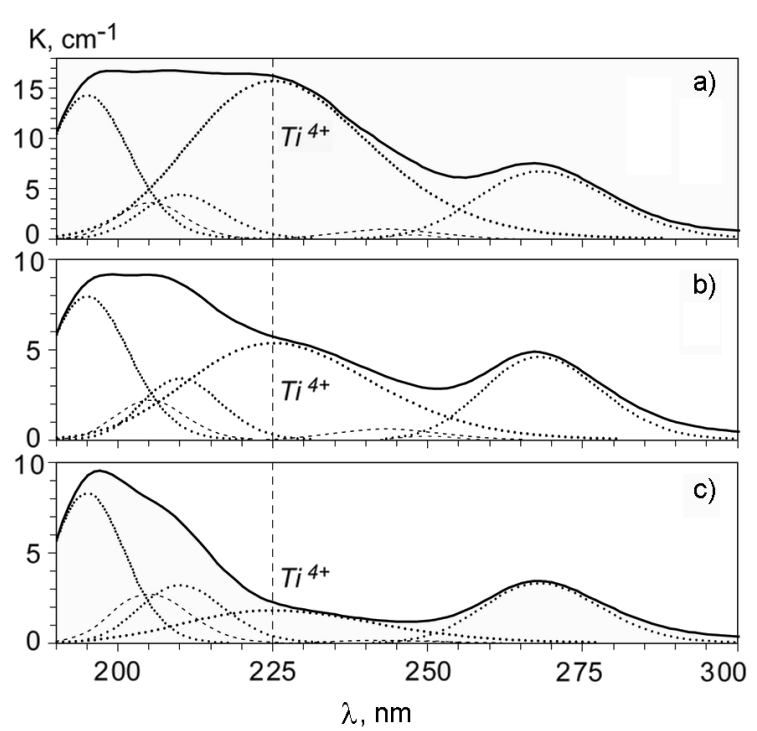

Fig. 5. Optical absorption spectra for OP Ti:sapphire grown in $\mathrm{Ar}+\mathrm{CO}+\mathrm{H}_{2}$ (a), and in $\mathrm{CO}+\mathrm{H}_{2}$ atmosphere after additional reducing annealing under less reducing (conditions IV) (b) and more reducing (conditions IV) (c) conditions. The results of the decomposition of the spectra into elementary Gaussian components are shown by dashed curves, the position of the maximum of the band is marked at $225 \mathrm{~nm}$.

points) $\left[\mathrm{Ti}^{4+}\right] /\left[\mathrm{T}^{3+}\right]$ and $\left[\mathrm{Ti}^{4+}\right]$ values depending on the total concentration of the activator $\left.\mathrm{Ti}_{\text {tot }}\right]=\left[\mathrm{Ti}^{3+}\right]+\left[\mathrm{Ti}^{4+}\right]$. The parameters used in the calculations (the temperature and composition of the medium) are given in Table 1. The experimental values are presented for the crystals grown in the medium $\mathrm{CO}+\mathrm{H}_{2}, \quad P\left(\mathrm{CO}+\mathrm{H}_{2}\right) \approx 0.03-$ 0.05 Torr (conditions I), and in the medium $\mathrm{Ar}+\mathrm{CO}+\mathrm{H}_{2} P_{m}=800$ Torr, $P_{\text {red }}=3-$ 5 Torr (conditions II-III), as well as for the crystals subjected to additional reducing annealing at $1900 \mathrm{~K}$ in the medium $\mathrm{Ar}+\mathrm{CO}+\mathrm{H}_{2}, \quad P_{m}=800$ Torr, $P_{\text {red }}=3$ Torr (conditions IV) and $P_{\text {red }}=5$ Torr (conditions V).

The calculated dependences (1), Fig. 4 obtained at $T=2327 \mathrm{~K}, \quad P\left(\mathrm{CO}+\mathrm{H}_{2}\right)=$ 0.03 Torr, $P_{\mathrm{H}_{2}} / P_{\mathrm{CO}}=0.01$ to a sufficient degree coincide with the experimental data. A good agreement is also observed between the experimental data for the crystals grown in the $\mathrm{Ar}+\mathrm{CO}+\mathrm{H}_{2}$ atmosphere and the calculations made for $T=2327 \mathrm{~K}$, $\mathrm{Ar}+\mathrm{CO}+\mathrm{H}_{2}, \quad P_{m}=800 \quad$ Torr, $\quad P_{\text {red }}=3-$ 5 Torr, $P_{\mathrm{H}_{2}} / P_{\mathrm{CO}}=0.1$ (the dependences 2, 3). The composition of the medium used in these calculations coincides with the one characteristic of the growth of the crystals [7-10]. At the same time, though for the crystals subjected to additional reducing annealing in $\mathrm{Ar}+\mathrm{CO}+\mathrm{H}_{2}$ atmosphere at $1900 \mathrm{~K}$ the power dependences $\left[\mathrm{Ti}^{4+}\right] /\left[\mathrm{Ti}^{3+}\right] \sim\left[\mathrm{Ti}_{\text {tot }}\right]^{-}$ $1 / 4$ and $\left[\mathrm{Ti}^{4+}\right] \sim\left[\mathrm{Ti}_{\text {tot }}\right]^{3 / 4}$ hold true (the dependences 6,7 ), the quantitative coincidence of the calculated (the dependences 4, 5) and experimental (the dependences IV, V) values is not observed. The calculated values exceed the experimental ones by more than three times. Preliminarily, such a fact may be explained taking into account the assumption $\left.\left(\mathrm{Ti}_{\text {tot }}\right]=\left[\mathrm{Ti}^{3+}\right]+\left[\mathrm{Ti}^{4+}\right]\right)$ used in the theoretical estimations, as well as the peculiarities of the optical absorption spectra of the crystals (Fig. 5).

As noted above, the values of $\mathrm{Ti}^{4+}$ have been estimated after decomposition of the spectra $K(\alpha)$ into the Gaussian components, with respect to the intensity of the optical absorption band with a maxima at $225 \mathrm{~nm}$. At the same time, as established by the earlier performed analysis of the optical absorption spectrum for the Ti:sapphire obtained under the reducing conditions [11], the spectral region of $190-250 \mathrm{~nm}$ contains not only the band with a maximum at $225 \mathrm{~nm}$ connected with the presence of the activator in the charge state $\mathrm{Ti}^{4+}$, but also the bands with maxima at 195 and $210 \mathrm{~nm}$, obviously caused by the defects of $F_{\mathrm{Ti}}$ type ( $F$-center near the titanium ion substituting $\mathrm{Al}^{3+}$ ) [25]. In this case some portion of $\mathrm{Ti}^{4+}$ ions may be contained in these complex defects and may not be taken into account while calculating the experimental $\left[\mathrm{Ti}^{4+}\right]$ value according to (2). In the crystals grown in $\mathrm{CO}+\mathrm{H}_{2}$ medium under low pressure [11] and in $\mathrm{Ar}+\mathrm{CO}+\mathrm{H}_{2}$ atmosphere (Fig. 5a), the intensity of such bands is low in comparison with that of the band with a maximum at $225 \mathrm{~nm}$. After additional reducing annealing the relative contribution of there bands increases (Fig. 5b, c), and the theoretical estimations made under the condition [ $\left.\mathrm{Ti}_{\text {tot }}\right]$ $=\left[\mathrm{T}^{3+}\right]+\left[\mathrm{Ti}^{4+}\right]$ considerably exceed the values of $\left[\mathrm{Ti}^{4+}\right]$ estimated according to (2). This explanation is confirmed by the observed correlation between the relative contribution of the bands with maxima at 195 and $210 \mathrm{~nm}$ at the rise of the reduction potential of the annealing medium (Fig. 5b, c) and the increase of the quantitative non-coincidence of the calculated and experimental values of $\left[\mathrm{Ti}^{4+}\right] /\left[\mathrm{Ti}^{3+}\right]$ and $\left[\mathrm{Ti}^{4+}\right]$ (the dependences 4,5 and the points IV, $\mathrm{V}$ in Fig. 4). 


\section{Conclusions}

Thus, the study of the charge state of the activator in the Ti:sapphire crystals grown by the method of HDC using carbon-containing constructional materials shows that for the crystals containing $0.03-0.1$ wt $\%$ of titanium grown in $\mathrm{CO}+\mathrm{H}_{2}$ medium under a pressure of $0.01-0.3$ Torr, the ratio of the activator quantity in the charge states $\left[\mathrm{Ti}^{4+}\right]$ and $\left[\mathrm{Ti}^{4+}\right]$ is $\approx 0.024-0.033$. For the crystals grown in $\mathrm{Ar}+\mathrm{CO}+\mathrm{H}_{2}$ atmosphere it is $\approx 0.014-0.017$ and decreases after the additional reducing annealing down to $\approx 0.0023-$ 0.0035 . The obtained approximate analytical dependences of $\left[\mathrm{Ti}^{4+}\right]$ and $\left[\mathrm{Ti}^{4+}\right] /\left[\mathrm{Ti}^{3+}\right]$ on the partial pressure of molecular oxygen and the total concentration of the activator provide an accurate description of the experimental data obtained for the Ti:sapphire grown by the method of HDC using carbon graphite materials in the capacity of thermal insulation. It is established that though at the rise of the total concentration of the activator the value of the ratio $\left[\mathrm{Ti}^{4+}\right] /\left[\mathrm{Ti}^{3+}\right] \mathrm{di}$ minishes to $\sim \mathrm{Ti}_{\text {tot }}{ }^{-1 / 4}$, the concentration of the activator in the charge state $\mathrm{Ti}^{4+}$ rises to $\sim \mathrm{Ti}_{\text {tot }}{ }^{3 / 4}$. This may be accompanied with the increase of the quantity of centers of absorption at $800 \mathrm{~nm}\left(\mathrm{Ti}^{3+}-\mathrm{Ti}^{4+}\right.$-centers $)$ and, consequently, by the decrease of the FOM. In conclusion it should be noted that the realized thermodynamic approach may be used for estimation of the degree of reduction of the activator in Ti-sapphire crystals grown by different methods using the technological media which contain the reducing components.

\section{References}

1. T.Fukuda, Y.Okano, N.Kodama et al., Cryst. Res. Technol., 30, 185 (1995).

2. R.Uecker, D.Klimm, S.Ganschow et al., Proc. of SPIE, 5990, 1 (2005).

3. A.Nehari, A.Brenier, G.Panzer et al., Cryst. Growth Des., 11, 445 (2011).

4. G.Alombert-Goget, K.Lebbou, N.Barthalay et al., Opt. Mater., 36, 2004 (2014).

5. D.B.Joyce, F.Schmid, J.Cryst.Growth, 312, 1138 (2010).
6. J.Dong, P.Deng, J.Cryst.Growth, 261, 514 (2004).

7. S.V.Nizhankovskii, A.Danko, E.V.Krivonosov, V.M.Puzikov, Inorgan. Mat., 46, 41 (2010).

8. A.Ja.Dan'ko, S.V.Nizhankovskiy, V.M.Puzikov et al., Crystallogr. Rep., 53, 1272 (2008).

9. A.Y.Danko, V.Polyakov, V.P.Seminozhenko, N.S.Sidelnikova, Technological Bases of Growing Sapphire Under Reducing Conditions, ISMA, Kharkov (2009).

10. S.V.Nizhankovskii, E.V.Krivonosov, V.V.Baranov et al., Inorgan. Mat., 48, 1243 (2012)

11. S.V.Nizhankovskii, N.S.Sidelnikova, V.V.Baranov, Phys. Solid State, 57, 763 (2015).

12. P.F.Moulton, J.Opt.Soc.Am.B, 3 3, 125 (1986).

13. A.J.Strauss, R.E.Fahey, A.Sanchez, R.L.Aggarwal, SPIE Laser and Nonliner Optical Materials 681, 62 (1986).

14. A.Sanchez, A.J.Strauss, R.L.Aggarwal, R.E.Fahey, IEEE J.Quant.Electron., 24, 995 (1988).

15. R.L.Aggarval, A.Sanchez, IEEE J.Quant. Electron., 24, 1003 (1988).

16. J.Stone-Sundberg, M.Kokta, A.Silberstein et al., Workshop: Technological Bottlenecks in CHISP Lasers, Paris, April 1-4 (2003).

17. N.Moskvin, V.A.Sandulenko, E.A.Sidorov, J.Appl. Spectrosc., 32, 1017 (1980).

18. S.K.Mahapatra, F.A.Kroger, J.Amer.Ceram. Soc., 60, 381 (1977).

19. A.Ya.Danko, N.S.Sidelnikova, Functianal. $M a-$ terials, 8, 271 (2001).

20. L.V.Gurvich, I.V.Weitz, V.A.Medvedev, Thermodynamic Properties of Individual Substances, Reference book: In 4 t., Vol.1. B.2. Science, Moscow (1978) [in Russian].

21. L.Gurvich, I.V.Weitz, V.A.Medvedev, Thermodynamic Properties of Individual Substances, Reference book: In 4 t., Vol.2. B.2. Science, Moscow (1979) [in Russian].

22. L.Gurvich, I.V.Weitz, V.A.Medvedev, Thermodynamic Properties of Individual Substances, Reference book: In 4 t., Vol.3. B.2. Science, Moscow (1981) [in Russian].

23. W.R.Rapoport, C.P.Khattak, Appl.Opt., 27, 2677 (1988).

24. http://www.gtat.com/products-and-servicesHEM-Tisapphire.htm

25. A.I.Syurdo, Author. Dis. Doctor. Sci. Sciences: 01.04.07. Ural State Technical University. Ekaterinburg (2007). 